\title{
Genetic causes of reproductive problems in the Bosnian women population
}

\author{
Mirela Mackic-Djurovic ${ }^{1}$, Dunja Rukavina², Lejla Ahmetas ${ }^{3}$ \\ ${ }^{1}$ Assistant Professor, Center for Genetic, Faculty of Medicine, University of Sarajevo, Sarajevo, Bosnia and \\ Herzegovina, ${ }^{2}$ Professor, Veterinary Faculty, University of Sarajevo, Sarajevo, Bosnia and Herzegovina, ${ }^{3}$ Research \\ Consultant, Bosnalijek, Pharmaceutical and Chemical Industry, Sarajevo, Bosnia and Herzegovina
}

Background: The causes of infertility and recurrent spontaneous abortions are diverse and numerous - including non-genetic and genetic factors - whereby the importance of genetic factors in pathogenesis of infertility is becoming more and more common. Chromosomal abnormalities and genetic defects can cause reproduction failures, and for this reason genetic analysis can play an important role in reproductive problems research. Aims and Objective: This study aims to determine the type and frequency of chromosomal aberrations in the female population sample, as well as to determine if the difference between groups with and without chromosomal aberrations was statistically significant. Materials and Methods: One hundred women aged 15-46 were included in the study, all having different reproductive disorder diagnoses and requiring karyotype analysis in the Sarajevo Medical Faculty Genetic Center. Cytogenetic analysis was performed on the peripheral blood, which was cultured for four days, using GTG banding forchromosomal analysis. Results: Out of 100 women included in the study, an abnormal karyotype was found in 16 of them (16\%). The difference between the frequency of normal and abnormal karyotype in women with reproductive problems identified in this study was found to be statistically significant. The pattern of chromosomal aberrations was similar to that reported in the previous cytogenetic studies with similar inclusion criteria. Conclusion: This fact should be taken in the consideration in order to estimate true etiology of reproductive problems and it is a valuable information in the process of genetic counseling and decision making in assisted reproductive technology.

Key words: Genetic causes; Recurrent spontaneous abortions; Structural and numerical chromosomal aberration

\section{Access this article online}

Website:

http://nepjol.info/index.php/AJMS DOI: 10.3126/ajms.v9i5.20407

E-ISSN: 2091-0576

P-ISSN: 2467-9100

\section{INTRODUCTION}

According to some information 60-80 million pairs a a year has problems with infertility. ${ }^{1}$ The aspects of genetics is important to detect the problem of infertility in time. In cases where genetic disorders in the background of these problems,it is essential to assess the risk of transmission of the same. By detecting changes in chromosome or gene, there is a possibility of giving precise genetic information about the risks of inheritance. ${ }^{2}$ Chromosomal aberrations represent one of the major reasons and causes of infertility and spontaneous abortions. Most important causes of infertility in women are polycystic ovary syndrome (PCOS), premature loss of ovarian function (POI), and recurrent miscarriages (RPL). Aberrant karyotype leads to repeated miscarriages in women. Abnormalities in chromosomes affect about $6.3 \%$ of infertile patients, and affect both sexes. ${ }^{3}$ Compared with the general population infertile couples have a higher level of chromosome aberrations.

Approximately $2.8 \%$ of infertile women have certain numerical abnormalities in sex chromosomes, while $2.1 \%$ of them wearer structural changes in autosomes translocation. $^{2}$ 


\section{MATERIALS AND METHODS}

In our research, 100 women participated having reproductive problems (sterility and habitual abortions) aged between $15-46$ years (mean $36.8 \pm 6.75$ ). Research was conducted at the Center for genetics at the Medical faculty of Sarajevo University.

Standard method of 72 hours cultivation of peripheral blood lymphocytes was applied. ${ }^{4}$ Cytogenetic analysis was performed according to instructions and rules given by International System of Human Chromosomal Nomenclature (ISCN). ${ }^{5}$ At least 25 mitotic cells were treated with $\mathrm{G}$ banding technique(GTG). ${ }^{6}$ If there was doubt of mosaic karyotype, 50 up to 100 cells have been analyzed. C-band has been applied for confirmation of chromosomal heteromorphy.

The results were analyzed using SPSS 20 (Statistical Package for the Social Sciences, IBM, NY, USA) for Windows OS.Chi square test was used for analyzing categorical variables.

\begin{tabular}{lcc} 
Table 1:The frequency of normal and abnormal \\
karyotype, Chi-square $(\chi 2)$ and value differences \\
considered significant \\
\hline Type of karyotype & $\mathbf{n}$ & $\%$ \\
\hline Normal karyotype & 84 & 84 \\
Abnormal karyotype & 16 & 16 \\
$\Sigma$ & 100 & 100 \\
Chi-square* & $186,8^{*}$ & \\
\hline${ }^{*}<<0,05$ & &
\end{tabular}

\section{RESULTS}

From the above mentioned participated women, 16\% are showing abnormal karyotype. In order to test whether there is a statistically significant difference between the proportion of normal and abnormal karyotype in the analyzed sample, chi-square $(\chi 2)$ test was made by SPSS 20 . The calculated $\mathrm{p}$ value was less than $0.05(\mathrm{p}<0,05)$, which shows that the difference between the proportion of normal and abnormal karyotype in women with reproductive problems is significant (Table 1).

Younger participants were 15 years old, and the oldest 46 years, a mean value of 30.97 years, with a standard deviation of \pm 6.9. In the Table 2 types are shown recorded chromosome aberrations divided based on the type of aberrant chromosomes (autosomal and sex chromosomes), and their frequency in the analyzed sample.

\section{DISCUSSION}

From this study the frequency of genetic causes in reproductive problems of Bosnian women were analysed. In the sample population, 16 percentages of chromosomal abnormalities was recorded. Only major abnormalities were cytogenetic analyzed and chromosome inversion 9 was included in the overall percentage.

Table 2 shows that the most karyotypes (four) with pericentric inversion of chromosome 9 in a group of

\begin{tabular}{|c|c|c|}
\hline Type of chromosomal aberration & The frequency of the analyzed sample & Karyotype \\
\hline \multicolumn{3}{|l|}{ Autosomes chromosomes } \\
\hline $\mathrm{T}$ & 1 & $46, X X, t(7 ; 11)(p 10 ; p 10)$ \\
\hline \multirow[t]{2}{*}{$\mathrm{RT}$} & 2 & $45, X X, \operatorname{rob}(13 ; 14)(q 10 ; q 10)$ \\
\hline & & $45, X X, \operatorname{rob}(21 ; 22)(q 10 ; q 10)$ \\
\hline \multirow[t]{4}{*}{ INV } & 4 & $46, X X$, inv9(p11;q13) \\
\hline & & $46, X X, \operatorname{inv} 9(\mathrm{p} 11 ; \mathrm{q} 13)$ \\
\hline & & $46, X X$, inv9(p11;q13) \\
\hline & & $46, X X$, inv9(p11;q13) \\
\hline Der & 1 & $46, X X, \operatorname{der} 3(3 ; 11)(q 29 ; q 13.13)$ \\
\hline \multicolumn{3}{|l|}{ Sex chromosomes } \\
\hline \multirow[t]{3}{*}{ TS+M } & 3 & $46, X X(35) / 45, X(15)$ \\
\hline & & $46, \mathrm{XX}(97) / 45, \mathrm{X}(3)$ \\
\hline & & $45, X(82) / 46, X$, marker $(18)$ \\
\hline \multirow{2}{*}{$\mathrm{TS}+\mathrm{M}+\mathrm{TF}$} & 2 & $45, X(37) / 46, X Y(63)$ \\
\hline & & $45, X(6) / 46, X Y(44)$ \\
\hline Del + TS & 1 & $46, X$, delX (q25?) \\
\hline $\mathrm{TS}+\mathrm{M}+\mathrm{INV}$ & 1 & $45, X(41) / 46, X, i(X)(q 10)(9)$ \\
\hline \multicolumn{3}{|l|}{ Autosomes+sex chromosomes } \\
\hline $\mathrm{TS}+\mathrm{M}+\mathrm{DS}$ & 1 & $45, X(90) / 47, X X,+21(6) / 46, X X(4)$ \\
\hline
\end{tabular}




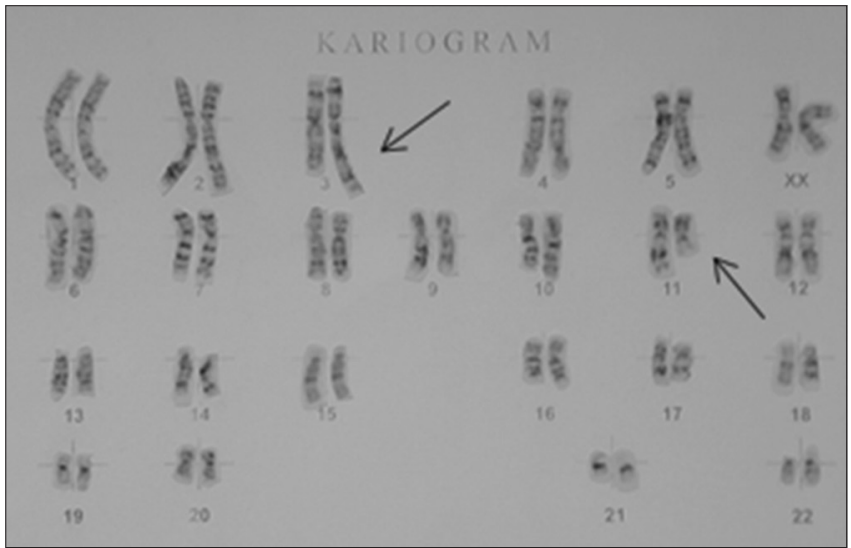

Figure 1: Karyogram 46,XX,der(3;11)(q29;q13.13)

autosomal chromosomes. Robertsonian translocation and reciprocal translocation were also recorded in this group with derivative chromosomes (Figure1). Subjects with a reciprocal translocation had one and the derivative chromosome respondents had three spontaneous abortion history.

From the aberrant group, seven karyotypes have been detected as Turner's syndrome. Six karyotypes had mosaic form (45,X/46,XX; 45,X/46XY), and only one had without mosaicism or partial deletion of chromosome X [46,X,delX (q25?)]. Two respondents with mosaic type $45, \mathrm{X} / 46, \mathrm{XX}$, as well as two with mosaic type $45, \mathrm{X} / 46, \mathrm{XY}$ are the Center sent on suspicion of Turner syndrome and/or amenorrhea, and one women with mosaicism 45,X/46,XX for sterility. Subjects with deletion of chromosome $\mathrm{X}$ is as diagnosis had oligomenorrhea and women with inversion of chromosome $\mathrm{X}$ amenorrhea. An interesting case is a woman with a triple mosaicism $[45, \mathrm{X}(90) / 47, \mathrm{XX},+21(6) / 46, \mathrm{XX}$ (4)], which involved aberration of autosomal and sex chromosomes. Through invasive prenatal diagnosis, she knew about her reason of two miscarriages. ${ }^{7}$ The authors of the previous cytogenetic studies have analyzed the incidence of abnormalities of autosomal and sex chromosomes in people with reproductive problems. Therefore, in this study made an analysis in order to determine whether there is a statistically significant difference between the two types of chromosome abnormalities covered by the sample. Of the 16 women with an abnormal karyotype, eight had abnormalities of autosomal chromosomes, seven abnormalities of sex chromosomes, and one woman had abnormality of autosomal and sex chromosomes. From the total number of analyzed samples, the percentage of abnormalities of autosomal chromosomes was 8\%,7\% sex chromosomes, and 1\% by abnormalities of autosomal and sex chromosomes.

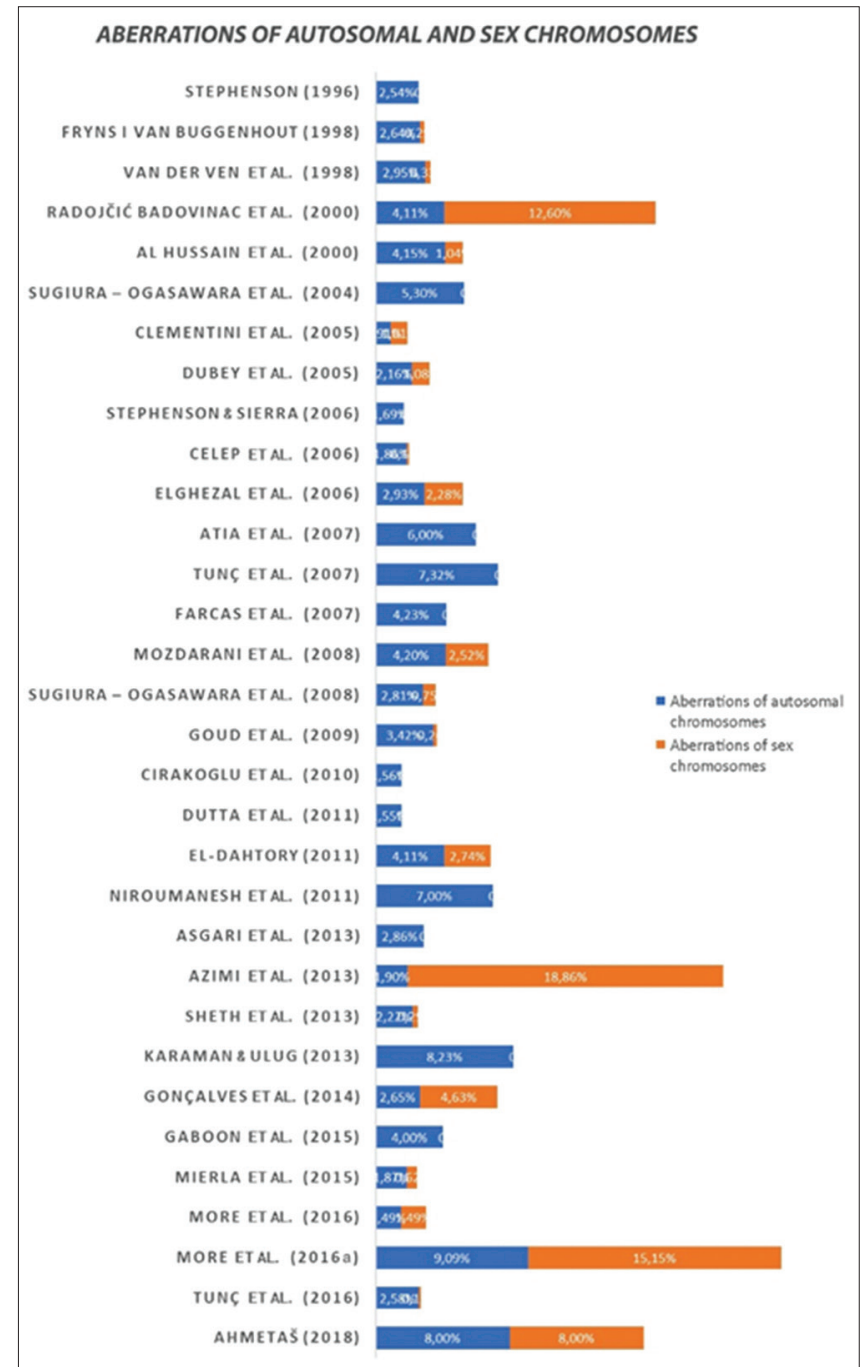

Graph 1: The percentage of autosomal and sex chromosomes aberrations in cytogenetic studies

In Graph 1 shows the percentages recorded abnormalities of autosomal and sex chromosomes in women in this study and previously published studies.

Previous studies showed that mostly there is a higher percentage of abnormalities of autosomal chromosomes, rather than sex chromosome. In contrast, some studies have reported that the higher percentage of abnormal sex chromosome ${ }^{8}$ have noted that $4.11 \%$ of autosomal chromosome abnormalities and $12.60 \%$ of sex, Clementine et al, ${ }^{9}$ which recorded $0.91 \%$ abnormalities of autosomal chromosomes and 1.01\% of sex, Azimi et al, ${ }^{10}$ which recorded $1.90 \%$ abnormalities of autosomal chromosomes and $18.86 \%$ of sex, More et al ${ }^{11}$ have noted that $9.09 \%$ of autosomal chromosome abnormalities and $15.15 \%$ of sex, and Goncalves et $\mathrm{al}^{12}$ have noted that $2.65 \%$ abnormal autosomal chromosomes and 4.63\% sex chromosomes. 
From the analysis criteria applied for inclusion of subjects in the study it can be concluded that higher percentages of autosomal chromosome abnormalities observed in studies included subjects with recurrent spontaneous abortions history, with the exception of the study conducted by Gonçalves et al. ${ }^{12}$ Studies that have recorded higher percentage of abnormalities of sex chromosomes rather than autosomal ones, had more patients included in the study, that had been diagnosed with primary and secondary infertility and sterility.

In this study, as previously stated, the diagnosis on the basis of which the patients were sent to the cytogenetic analysis at the Center for Genetics were miscarriage in addition to other abnormalities. In this case $54 \%$ of waste in the diagnosis of spontaneous abortion, or the infertilitas diagnosis, and the remaining $46 \%$ of the waste to other diagnosis. For diagnosis infertilitas the largest number of abnormal karyotypes, six, and five on the aberrations of autosomal chromosomes. Other abnormalities were observed in 10 patients with other diagnoses. Given that in this study, $46 \%$ of the waste and to other diagnoses, except spontaneous abortions, and that for other diagnoses total recorded higher number of chromosome abnormalities indicated may be the reason that in this study, is not statistically significant difference between the proportion of abnormalities of autosomal and sex chromosomes.

The frequency of chromosome abnormalities in this study was $16 \%$, which is a higher percentage than the frequency reported in other studies. ${ }^{13,14}$ If the inversion of chromosome 9 consider normal form karyotype and four recorded inversion exclude such chromosome abnormality, gives a total of 12 abnormal karyotypes recorded in a sample of 100 women it consists of $12 \%$. Though a higher percentage of the most frequently recorded in the current study compared to findings of the previous reported studies. ${ }^{15}$ The reason for the high incidence of chromosomal abnormalities could be because in this study cytogenetic analyzes there were cases with more than one recurring miscarriages, while most of the studies included cases with two, three or more recurrent miscarriages. In addition to the recorded spontaneous abortion history, in this study included women with other diagnoses, and it Sterilitas primarius and secundaria implying that there might be conception, as well as women with amenorrhea, oligomenorrhea, suspicion of Turner syndrome, and women who have had offspring with abnormal karyotype. So this selected group of women who went through many filters including tests of obstretičara/gynecologist, endocrinologist and their suspicion was on chromosomal abnormality when they were sent to the Center for Genetics at the cytogenetic testing. It is possible that all the above (wider criteria inclusion in the study with the involvement and cases with history of one miscarriage, rather selected group of respondents, the number of respondents contributed to the higher percentage of recorded chromosome abnormalities in this study compared to results of other studies.

\section{CONCLUSION}

The conclusion of this study is that chromosomal abnormalities are more frequent in the population of patients with reproductive problems (sterility and habitual abortions) when compared with general population. This fact should be taken in the consideration in order to estimate true etiology of reproductive problems and it is a valuable information in the process of genetic counseling and decision making in assisted reproductive technology. Once again, the study has proven and confirmed how unnecessary classical cytogenetic tecniques have been.

\section{REFERENCES}

1. Poongothai J, Gopenath TS and Manonayaki S. Genetics of human male infertiliy. Singapore Med J 2009; 50(4): 336-347.

2. Stipoljev F. Genetic causes of infertility. Medicina 2007; 43:279284.

3. Moorhead PS, Norvell PC, Mellman WJ, Battips DM and Hungerford DA. Chromosome preparations of leukocytes cultured from human peripheral blood, Exp Cell Res 1960; 202:613-616.

4. Shaffer LG and Tommerup N. An International System for Human Cytogenetic Nomenclature. Basel: Karger, 2013.

5. Barch M.J. The ACT Cytogenetics Laboratory Manuel, $2^{\text {nd }}$ ed. New York: Raven Press, 1991.

6. Kayed HF, Mansour RT, Aboulghar MA, Serour GI, Amer AE and Abdrazik A. Screening for chromosomal abnormalities in 2650 infertile couples undergoing ICSI. Reprod Biomed Online 2006 Mar;12(3):359-70.

7. Mačkić-Đurović $M$, Stomornjak-Vukadin $M$ and Ibrulj S. Turner Syndrome: A Unique Mosaic Case with 45, X/47, XX,+21/46, XX Cell Lines. Iranian Journal of Medical Sciences. In press 2018.

8. Radojčić Badovinac A, Buretić-Tomljanović A, Starčević N, Kapović M, Vlastelić I and Randić L. Chromosome studies in patients with defective reproductive success. Am J Reprod Immunol 2000;44(5): 279-283.

9. Clementini E, Palka C, lezzi I, Stuppia L, Guanciali-Franchi P and Tiboni GM. Prevalence of chromosomal abnormalities in 2078 infertile couples referred for assisted reproductive techniques. Human Reproduction 2005;20(2): 437-442.

10. Azimi C, Khaleghian M and Farzanfar F. A retrospective chromosome studies among Iranian infertile women: Report of 21 years. Iranian journal of reproductive medicine 2013;11(4): 315-324.

11. More R, More MP, Borate S and Gangane SD. Cytogenetic study in females with primary infertility. Journal of Medical Science and Clinical Research 2016;04(01): 8941-8944.

12. Gonçalves RO, Santos WVB, Sarno M, Cerqueira BAV, 
Gonçalves MS and Costa OLN. Chromosomal abnormalities in couples with recurrent first trimester abortions. Revista Brasileira de Ginecologia e Obstetrícia 2014;36(3): 113-117.

13. Dutta UR, Rajitha P, Pidugu VK and Dalal AB. Cytogenetic abnormalities in 1162 couples with recurrent miscarriages in southern region of India: report and review. Journal of assisted reproduction and genetics 2011; 28(2): 145-149.
14. More RM, More MP, Borate S and Gangane SD. Cytogenetic study in females with secondary infertility. Journal of Medical Science and Clinical Research 2016;04(08): 11834-11838.

15. Boivin J, Bunting L, Collins JA and Nygren KG. International estimates of infertility prevalence and treatment-seeking: potential need and demand for infertility medical care. Human reproduction 2007; 22(6): 1506-1512.

\section{Authors Contribution:}

MMD- Concept and design of the study, manuscript preparation, statistically analyzed and interpreted, critical revision of the manuscript; DR- Critical revision of manuscript and review of the study; LA- Conceptualized study, literature search, helped in preparing first draft of manuscript, statistically analyzed, collected data;

Work attributed to: Center for genetics, Faculty of Medicine University of Sarajevo, Čekaluša 90, 71000 Sarajevo, Bosnia and Herzegovina.

Orcid ID:

Dr Mirela Mačkić-Đurovi - (D) https://orcid.org/0000-0001-7198-5642

Dr Dunja Rukavina - (i) https://orcid.org/0000-0002-0937-6544

Mr Lejla Ahmetaš - (D) https://orcid org/0000-0002-3175-9525

Source of Support: Nil, Conflict of Interest: None declared. 